\title{
Evolution to Smart Learning in Public Education: A Case Study of Korean Public Education
}

\author{
Taisiya Kim ${ }^{1}$, Ji Yeon $\mathrm{Cho}^{2}$, and Bong Gyou $\mathrm{Lee}^{2}$ \\ ${ }^{1}$ Graduate School Department of Management of Technology, \\ Yonsei University, South Korea \\ ${ }^{2}$ Graduate School of Information, Yonsei University, South Korea \\ \{lucky8619, jy.cho, bglee\}@yonsei.ac.kr
}

\begin{abstract}
The purpose of this study is to introduce a new paradigm called "Smart Learning" in South Korea. The adoption of highly advanced Information Technology (IT) in education has been a global issue for many years. The Smart Learning paradigm in Korea is a convergence concept of Ubiquitous Learning (u-Learning) and Social Learning. This study examined the Smart Learning education system through a SWOT analysis of Korean public education. Thus, this study provides strategic implications for the countries that are in the process of promoting the Smart Learning education program.
\end{abstract}

Keywords: Smart Learning, Public Education, South Korea, SWOT analysis.

\section{Introduction}

Recently, the introduction of highly advanced technology to establish a new digitalized education environment has become a major global issue. Whenever new technologies emerge, many issues arise regarding how they can be introduced to support effective learning. Social technology has recently become a platform for the educational environment. In particular, many countries are currently interested in educational methods using smart devices and Social Network Services (SNS).

Advanced information technologies enable educational environment to broaden place, content, and forms of education. Digital textbooks and smart devices are replacing paper books, and the potential forms of education are becoming unlimited. For example, SNS has become an educational instrument. Consequently, telecommunication companies and portal companies are now interested in education business.

The global enterprise Apple announced plans to launch a new business in the global online education market. Apple plans to launch a digital textbook and has established a partnership with major publishers. Samsung Electronics has also announced that it will undertake an online learning service in Korea [1].

The Korean government has recognized the Electronic Learning (e-Learning) industry, the convergence industry of IT and educational services, as a fast-growing and high-value industry. In 2004 year, the government supported the policy on e-Learning industry development Act and made an investment in initiating the development of the e-Learning industry. As a result, Korea has become the leader in 
using e-Learning in public education, and it is developing a Smart Learning system at the moment. Smart Learning is a new concept in education, and it has recently started being used in Korea. The Korean government is now beginning to introduce a new concept of a Smart educational environment based on strong IT infrastructure and advanced social technologies.

Therefore, the objective of this study is to introduce the concept of Smart Learning by analyzing the case of Korea. This study conducted a SWOT (Strengths, Weaknesses, Opportunities, and Threats) analysis of Korean public education to analyze activating strategies for Smart Learning. Section 2 examines the concept of Smart Learning, and Korea's status in the educational market. Then, section 3 analyzes a case study regarding Smart Learning in Korean public education. Section 4 includes strategic and political implications, and the final section is the conclusion. This study can offer useful guidelines for countries that are in the process of improving their education systems with innovative technologies.

\section{Smart Learning Overview}

\subsection{Evolution of Smart Learning}

Recently, IT has been regarded as a solution for improving the quality of education. In this sense, the use of advanced technologies in the field of education has increased significantly and promoted a paradigm shift in the educational environment over the last decade [2]. Many countries expect IT to enhance the quality of education and to expand the educational industry. Therefore, the utilization and implementation of advanced technology that comprise this new learning environment is very important to the Korean government. That is why the government chose 'e-Learning' as a top priority project that will be worked on for the next few years.

In this situation, IT and the educational environment have been changing significantly, and the use of IT in education has increased rapidly for last 10 years. For example, there has been a major paradigm shift from e-Learning, which was defined as computer-based training, to Mobile Learning (m-Learning), which was driven by the advancement in mobile and wireless technologies [2], [3], [4]. m-Learning has improved a great deal more than e-Learning in terms of the flexibility of location, cost of a device, ease of use, and timely application [4]. m-Learning is very similar to eLearning, but the only major difference is the use of mobile devices and wireless technology in the former. The development of IT has caused further changes in the educational environment, moving it away from the m-Learning environment toward the Ubiquitous Learning (u-Learning) environment. The u-Learning environment is an educational environment that allows students to study anytime and anywhere through diverse terminals, without limitations of time, place, or environment [2], [5], [6], [7]. Recently, the field of education has become interested in Social Learning, which is the use of smart devices and SNS services as educational instruments. Through social learning, students can share knowledge through their SNS and connect with teachers by tagging and sharing multimedia content that they have created. However, the adoption of social technologies in the educational system can cause privacy and copyrighting 
issues, among other issues. Related studies have just begun, and the effect of using social networking technologies in education is becoming an issue [8].

Recently in Korea, the Smart Learning paradigm, which combines u-Learning and social learning, has been emerging [9]. The evolution to Smart Learning is expected to improve the educational environment to advanced level regarding device, network, education program etc. However, discussions on Smart Learning have just begun in Korea, and the related studies are insufficient.

\subsection{Concept of Smart Learning}

So far there is no clear definition of Smart Learning. Related scholars and people who are involved with education business are discussing that the concept of Smart Learning should not be limited to just utilizing smart devices. Thus, the government, academia, and the educational industry have been working on defining and categorizing Smart Learning. At the Smart Learning Korea forum 2010 [9], a concept of Smart Learning was proposed as follows: first, it is focused on humans and content more than on devices; second, it is effective, intelligent tailored-learning based on advanced IT infrastructure [10]. Also, Kwak Duk-hoon, president and CEO of EBS (Korea's Educational Broadcasting System), said the term "Smart Learning" was first used in Korea. Then, what is the broad concept of Smart Learning in Korea?

MEST (The Korean Ministry of Education, Science and Technology) defined Smart Learning as Self-directed, Motivated, Adaptive, Resource-enriched, and Technology-embedded [11]. More information on S.M.A.R.T Learning promoted by MEST is as follows:

- S: Self-Directed, which means that the education system is progressing toward a self-learning system more than ever. Students' roles transition from knowledge adopters to knowledge creators. Also, teachers become facilitators of learning.

- M: Motivated means education becomes experience centered and involves learning by doing; creative problem solving and individualized assessment are pursued.

- A: Adaptive means strengthening of the education system's flexibility and tailoring learning for individual preference and future careers.

- R: Resource-enriched means that Smart Learning utilizes rich content based on open market, cloud education services from both public and private sectors. In other words, it expands the scope of learning resources to include collective intelligence, Social Learning.

- T: Technology-embedded means that in the Smart Learning education environment, students can learn anywhere, any time through advance technologies. Fig. 1 shows the holistic concept of SMART education in Korea.

Consequently, Smart Learning in Korea is a new paradigm using IT and network infrastructure in school education. The Smart Learning environment allows students to use all available learning devices anywhere and anytime, even social media. Students can attend courses at their own pace and are able to access only the elements of the course that pertain to them. The cutting-edge IT that is used actively in Smart 
Learning is called Smart Technology. Social network computing in particular is an important factor of mutual cooperation in the learning process that compensates for the limitations of e-Learning.

But so far, the government, academia, and the educational industry have been working on defining and establishing categories for Smart Learning. The field of education needs to consider a plan of mutual study with teachers, schoolmates and efficient, phased use of social network. The technological environment is transitioning from the use of smart devices to virtual reality, and augmented reality; therefore, the government, academia, and industry research aims to find ways to converge existing technology. Also, they are currently discussing possible ways to construct the environment using high-quality content at an affordable rate [9].

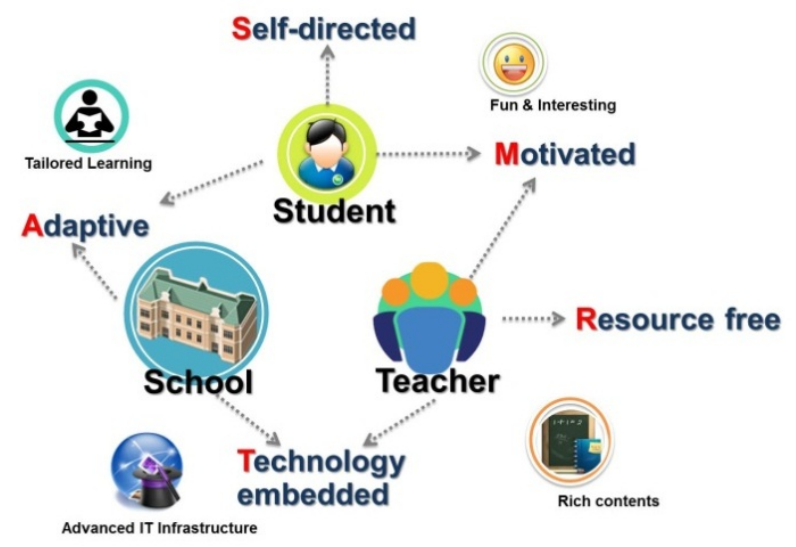

Fig. 1. SMART Education in Korea

\subsection{The Current Status of IT Use in Korean Public Education}

As noted, the Korean government has recently made an effort to establish an educational environment using advanced IT, such as e-Learning or u-Learning, in public education. Korea has an excellent information and communications infrastructure essential to the digitalized educational environment. High-speed internet has been installed nationwide, and there are a number of leading electronics companies in Korea like Samsung and LG that are engaged in developing smart device and telecommunication technologies. Recently, the supply of smart devices such as smartphones and smart pads has been growing rapidly, and new education paradigms like Smart Learning have been developed. This cutting-edge technological environment in Korea regarding broadband internet and devices has had a profound impact on the education industry and related policies. These are the reasons that, for the last few years, the Korean government has recognized the e-Learning education program as the future growth engine. The government's recent master plan has been focused on the evolution of Smart Learning environments and secure educational services with social technologies. The Korean government has already introduced 
e-Learning and $\mathrm{u}$-Learning in public education and made a massive investment in that field to solve the current problems in education and to respond to the new paradigm of education environment.

As a result, Korea has already established e-Learning programs in public education since 2004. In 2009 year, about $45 \%$ of all Koreans have had the experience of using e-Learning content, and $26.2 \%$ of all educational courses have been conducted through e-Learning on more than one occasion [12]. Specifically, the Korean government is currently trying to secure national competitiveness by achieving global standardization in the digital learning environment based on outcomes from years of pilot projects. The government has consistently promoted e-Learning and devices such as digital textbooks. Now, the Smart Learning education system is being targeted as a new growth engine. Social education, related to Smart Learning, is also garnering attention, and the IPTV (Internet Protocol Television) industry is also trying to change the Smart education paradigm. The introduction of Smart Learning is attracting interest from the media and telecommunication operators. It is already having a positive impact by broadening the education industry.

\section{Case Analysis of Korean Public Education}

\subsection{Strengths}

Smart Learning consists of advanced infrastructure, and rich, fun content that can be taught in an individualized manner. The Korean educational environment has sufficient infrastructure; on average it uses $87.71 \%$ of cable, $12.08 \%$ of wireless, and $0.10 \%$ of satellite and other internet networks in public schools. From 1997 to 2008, the government invested around 3.46 billion dollars in infrastructure[11]. Also, Korea is promoting a pilot project that is focused on testing the digital textbooks used for Smart Learning. Classroom infrastructure includes an electromagnetically-induced Tablet PC with a 12-inch monitor and a computer that is installed for the teacher [2]. Remote support and management functions are included in the teacher's Tablet PC to check the students' learning activities. The school network blocks illegal access from the outside and prevent disclosure of the students' profiles.

Inside and outside the classroom, students are available to use digital textbooks; this enables them to be more active and cultivate their ability to retain information longer and enjoy classes more. Digital textbooks cover six subjects in the fifth and sixth grades (Korean, English, Mathematics, Social Studies, Science, and Music) and give students an opportunity to prepare and review the subjects without carrying a bunch of textbooks.

\subsection{Weaknesses}

Content area is one of the weaknesses of the Korean Smart Learning environment. Most Korean students study in private institute academies after school. In 2010, over 25,000 private institute academies registered with the Seoul Metropolitan Office of Education [13]. Every institute has its own content and knows how to teach students efficiently. 
Whereas Smart Learning has to meet the demands of the systematic educational program, there is a lack of organizations to control the high quality content necessary for effective tailored learning.

The Korean digital book pilot project uses a school network that guarantees security; however, because the network has a low bandwidth, it cannot guarantee a reasonable access speed for accessing the internet. Thus, security is the most important factor for this project in public education.

However, live communication is the main factor in Smart Learning, and a school network could be too weak to support the service. Smart Learning is connected to SNS websites; therefore, it is exposed to more security risks than previous internetbased learning environments.

Historically, Korean public education had focused on the cramming method of teaching. Therefore, the social demand for Smart Learning is urgent in the Korean education market. The government is trying to increase innovation, life, and career skills in young population.

\subsection{Opportunities}

The supply rate of smart devices in Korea is high enough for applying Smart Learning. The Seoul Metropolitan Government predicts that the smart device supply rate in Korean will occupy almost $80 \%$ of population or even more, by 2015 . In addition, people use the internet 5.4 days each week. These facts show that there are many opportunities for Smart Learning to be applied in the Korean education system.

The Korean e-Learning system is led by government organizations that see the opportunity to make a systematic investment in the Smart Learning system. Since 2007, MEST (Korean Ministry of Education, Science and Technology) and KERIS (Korea Education and Research Information Service) have promoted a new concept for a public educational environment based on advanced IT infrastructure and a u-Learning environment. MEST and KERIS have tried to introduce a successful learning environment by developing and distributing digital textbooks in line with the future education paradigm [2].

Most Korean students rely on private institute academies, and the high price of private education is a burden for parents. Also, most of the qualitative academies are decentralized in specific parts of town, leading to the falling population of young students in such academies. Generalization of Smart Learning could prevent students from having to go to the other institutes. The government will also support a nationwide open content market containing a variety of learning materials so that users may have access to high-quality educational information at a low cost.

The approach to teaching in Smart Learning provides a tailored service to suit the individual needs and level of each student. In traditional public education, it is usually difficult to teach students individually. Tailored learning is the main strength of Smart Learning, and communication with tutors continuously doubles students' motivation for learning. 


\subsection{Threats}

The major threat of the Smart Learning system is standardization. In the process of communicating and sharing content, devices, infrastructure, and system standardization are necessary. Even though the Korean Smart Learning system is compatible with each other, new infrastructures of global enterprises could change the system. Global standardization about Smart Learning is uncertain, and changes in global market standardization can affect the Korean education market.

In addition, Korean parents are especially sensitive to their children's education, and recording students' learning abilities could increase parents' interference in a negative way. Monitoring children could result in making them more unstable rather than improving their confidence and performance in class.

There is also an expectation that private institute academies will oppose the Smart Learning system in public schools. One of the reasons is instructors unemployment. Whereas the goal of Smart Learning is to decrease the cost of private institute academies, over 25,000 of these academies are already systemized in Korea's education market. The spread of the Smart Learning system in public education programs could affect the decrease of private institute academies, and later it could cause unemployment for instructors.

\section{$4 \quad$ Analysis Results and Implications}

The results of the study show that the strengths of the Korean Smart Education System are its infrastructure, devices, and secured network. The implications for each result are as follows.

Table 1. SWOT analysis of the Korean Smart Education System

\begin{tabular}{|c|c|}
\hline Strengths & Weaknesses \\
\hline $\begin{array}{l}\text { - Sufficient classroom infrastructure } \\
\text { Digital textbook with six public school } \\
\text { subjects } \\
\text { School network to prevent disclosure of } \\
\text { students' profiles }\end{array}$ & $\begin{array}{l}\text { - Lack of high-quality content } \\
\text { - Few content management organizations } \\
\text { - School network has a low bandwidth for } \\
\text { internet use } \\
\text { - Cramming method of teaching }\end{array}$ \\
\hline Opportunities & Threats \\
\hline $\begin{array}{l}\text { High supply rate of smart devices } \\
\text { - Government-led increases in systematic } \\
\text { investments in Smart Education } \\
\text { - Increased number of young students in } \\
\text { the population } \\
\text { High-quality educational information at } \\
\text { a low cost } \\
\text { Tailored learning service doubles the } \\
\text { motivation of learning }\end{array}$ & $\begin{array}{l}\text { - Global standardization } \\
\text { - Parents' interference } \\
\text { - Private institutes' oppose and instructors' } \\
\text { unemployment }\end{array}$ \\
\hline
\end{tabular}


First, global companies like Samsung and LG are active in producing smart devices. The solid infrastructure and secure content controlled by the government will ensure the systematic development of Smart Learning and may eventually lead to an increase in the population of young students. In countries with expensive private education, Smart Learning is a solution with the potential to decrease the cost of after-school academies.

Second, through the cooperation of government departments, weaknesses such as a lack of quality content and management organizations could be minimized. It is important to have diverse content, but qualitative and tailored content is more important in public education. Korean EBS (Educational Broadcasting System) possesses a great deal of qualitative content and already has experience with cooperating with government organizations. EDUNET tries to create an open market in which public, private, and individual outstanding content could be used for educational purposes. Almost 6.20 million members already have joined EDUNET, and the company has around 5.5 million sources of information. Therefore, the cooperation of stakeholders like government departments, broadcasting, and telecommunications companies should lead to the creation of valuable services for the Smart Learning system.

Third, although the infrastructure is at a high level, global standardization is also an important issue, and Korean government organizations have conducted meetings on e-Learning standardization. The outcomes are going to be foundations for Smart Learning. In addition, due to the lack of high-quality content and credible organizations, parents' interference could increase and potentially threaten the Smart Learning environment. To overcome such weaknesses and threats, secured organizations that are capable of providing quality content are needed to alleviate the public's anxiety and fear of change [13].

\section{Conclusion}

The advancement of IT and networks has resulted in the emergence of ubiquitous computing environments and educational systems [2]. The public education system in Korea is preparing for the launch of Smart Learning educational service based on cloud computing services. Korea has been active in instituting e-Learning in public education, it is especially important to make a model of the case. To promote this new service, an analysis of possible strengths, weaknesses, opportunities, and threats, is necessary. Other countries are also planning educational programs based on social devices. However, like AT\&T and Apple, which are promoting pilot project on m-Learning in ACU (Abilene Christian University), most of the projects are supported by private companies.

This study analyzed the Korean Smart Learning education system with the goal of introducing a new education paradigm. The SWOT analysis explains Korean educational environment in general as well as the specific pilot Smart Learning case. Results of the analysis show the main solutions for vitalizing Smart Learning with consideration for a prudent public or a set of content management organizations. 
Such results are expected to have strategic implications for countries that are in the process of promoting the Smart Learning education system.

Acknowledgement. This research was supported by the KCC (Korea Communications Commission), Korea, under the CPRC(Communications Policy Research Center) support program supervised by the KCA (Korea Communications Agency) (KCA-2012-0902-1).

\section{References}

1. Park, S.: [MWC 2012] Samsung is going into digital textbook business... Opening 'Learning Hub Zone'. Etoday (March 20, 2012)

2. Kim, S.J.: Developing a framework of u-Learning for research and practice. Doctoral dissertation, Yonsei University (2010)

3. Lee, B.G., Kim, S.J., Park, K.C., Kim, S.J., Jeong, E.S.: Empirical analysis of learning effectiveness in u-Learning environment with digital textbook. KSII Transactions of Internet and Information Systems 6(3), 869-885 (2012)

4. Milrad, M.: How should learning activities using mobile technologies be designed to support innovative educational practices? In: Sharples, M. (ed.) Big Issues in Mobile Learning: Report of a Workshop by the Kaleidoscope Network of Excellence Mobile Learning Initiative, pp. 28-30. University of Nottingham, Nottingham (2007)

5. Chen, Y.S., Kao, T.C., Sheu, J.P., Chiang, C.Y.: Mobile Scaffolding Aid-Based Bird Watching Learning System. In: Proc. of IEEE International Workshop on Wireless and Mobile Technologies in Education (WMTE 2002), pp. 15-22 (2002)

6. Huh, H.O., Seo, S.S., Kang, E.S., Jeon, B.K., Jang, K.Y., Kye, B.K., Ko, B.S.: Research on developing a next generation learning model in a Ubiquitous computing environment. Korea Education \& Research Information Service. Research report KR 2006-4 (2006)

7. Jeong, S.M., Go, B.S., Seo, J.H., Sin, S.U.: Understanding of u-Learning. Korea Education \& Research Information Service. Research report RM 2005-54 (2005)

8. Lockyer, P.: Integrating social networking technologies in education: A case study of a formal learning environment. In: 8th IEEE International Conference on Advanced Learning Technologies, Santander, Spain, July 1-5 (2008)

9. Noh, K.S.: An exploratory study on concept and realization conditions of Smart Learning. The Journal of Digital Policy \& Management 9(2), 79-88 (2011)

10. Gwak, D.: The meaning and predict of Smart Learning. Smart Learning Korea Proceeding. Korean e-Learning Industry Association (2010)

11. MEST: Ministry of Education, Science and Technology of the Republic of Korea, Smart education promotion strategy, President's Council on National ICT Strategies (2011)

12. Korea Institute for Electronic Commerce and Korea Ministry of Knowledge Economy: e-Learning industry status survey. Korea Institute for Electronic Commerce (2008)

13. Todd, R.W.: Fear of change impedes cloud adoption for many companies. CIO BIZ (August 8, 2011) 